\title{
DOUBLE FREE FUNCTIONING MUSCLE TRANSFERS FOR BRACHIAL PLEXUS INJURIES: A CASE REPORT
}

\author{
Heri Suroto $^{1^{*}}$, Teddy Heri Wardhana ${ }^{1}$, Farindra Ridhalhi ${ }^{2}$ \\ ${ }^{1}$ Staff of Orthopaedic and Traumatology Department, Faculty of Medicine, Universitas \\ Airlangga/Dr Soetomo General Hospital, Surabaya \\ ${ }^{2}$ Resident of Orthopaedic and Traumatology Department, Faculty of Medicine, Universitas \\ Airlangga/Dr Soetomo General Hospital, Surabaya \\ *Corresponding Author: Heri Suroto, Senior Consultant of Orthopaedic and Traumatology \\ Department, Faculty of Medicine, Universitas Airlangga, J1. Prof. Dr. Moestopo 6-8, Surabaya. \\ E-mail: hsuroto2000@yahoo.com
}

\begin{abstract}
ABSTRAK
Transfer otot untuk cedera pleksus brakialis adalah salah satu pilihan untuk memperbaiki fungsi ektremitas atas. Pada umumnya transfer otot ini menggunakan satu otot yaitu otot gracillis. Teknik menggunakan dua otot donor untuk memfungsikan anggota gerak atas patut dipertimbangkan untuk kualitas fungsi yang lebih baik. Laki-laki 36 tahun dengan cedera pleksus brakialis komplit C5-T1 kiri akibat kecelakaan sepeda motor. Dilakukan tindakan transfer otot fungsional ganda (double FFMT) dengan menggunakan otot gracilis dan otot adduktor longus dengan sumber arteri thoracho akromialis, serta saraf frenikus dan saraf assesorius. Otot gracilis digunakan untuk fleksi jari-jari sedangkan otot adduktor longus digunakan untuk fleksi siku. Evaluasi satu tahun pasca operasi menunjukkan pasien telah mampu secara aktif melakukan gerakan fleksi dari siku dengan kekuatan skala 3 serta fleksi dari jari-jari dengan kekuatan skala 1.Tindakan transfer otot fungsional ganda efektif untuk mencapai gerakan fungsional siku dan tangan sekaligus.
\end{abstract}

Kata kunci: cedera pleksus brakhialis, transfer otot fungsional

\begin{abstract}
Free functional muscle transfer for brachial plexus injury is one of the alternatives to repair the upper extremity function, where usually one type of muscle is used, the gracillis. The method of using two donor muscles to restore the motor function is worth considering for a better improvement of the quality. A 36 years old man with a complete left brachial plexus injury from C5-T1 due to motorcycle accident. A double free functional muscle transfer was performed using the gracillis muscle and the adductor longus muscle with the arterial source from the thoraco-acromial artery with the phrenic and accessory nerves. The gracillis muscle is used to flex the fingers while the adductor is used for flexing the elbow. A one year postoperative evaluation showed the patient was already capable of flexing his elbow with the muscle score of 3 and also the fingers with the muscle score of 1 . The double free functional muscle transfer procedure is effective in achieving the moving function of both the elbow and the hand.
\end{abstract}

Keywords: brachial plexus injury, free functional muscle transfer

\section{PENDAHULUAN}

$\begin{array}{rrrr}\text { Cedera pleksus brakialis adalah } & \text { menyebabkan perbaikan fungsi jarang dapat } \\ \text { cedera yang menghancurkan yang dilakukan. Jika pasien tersebut datang }\end{array}$


terlambat, maka beberapa pilihan operasi saraf yang tersedia menjadi tidak aplikatif. Dalam kasus ini, terapi yang paling mungkin dilakukan untuk mengembalikan fungsi adalah Functioning Free Muscle Transfer (FFMT). Pada prosedur FFMT digunakan otot yang sehat beserta dengan pedikel vaskular dan saraf motorik yang diambil dari donor yang jauh dari resipien dan ditransfer untuk mengembalikan fungsi anggota tubuh. ${ }^{1,2}$

$$
\text { Cedera pleksus brakhialis }
$$

berdasarkan waktu pemberian terapi dibagi menjadi terapi segera, awal, atau terlambat. Misalnya luka tikam pada pleksus brakialis paling baik diterapi segera ketika aproksimasi ujung saraf dianggap cukup. Dengan prosedur tersebut kemungkinan besar akan menghasilkan outcome fungsional yang baik, terutama pada lesi pleksus bagian atas. Perbaikan awal terlihat dalam 8-12 minggu pasca cedera. Indikasi terapi segera termasuk cedera pleksus dengan nyeri berat, adanya pseudomeningokel pada resonansi magnetik (MR) myelografi, tanda Horner positif, dan kelumpuhan diafragma terkait. Tanda-tanda ini menunjukkan trauma yang parah pada pleksus dengan sedikit atau tidak ada potensi untuk pemulihan spontan. Intervensi awal, dalam kasus seperti itu, diharapkan untuk mendapatkan kembali beberapa fungsi yang bermanfaat. Mayoritas lesi pleksus brakialis merupakan cedera traksi dan membutuhkan periode pengamatan hingga 3-5 bulan. Pada saat ini, edema jaringan telah teratasi dan dengan pemulihan cedera neuropraksi, memungkinkan demarkasi yang jelas antara saraf yang lesi dan tidak lesi. Cedera proyektil pleksus brakialis sangat berbeda dengan cedera traksi. Proyektil kecepatan rendah memiliki prognosis baik dengan manajemen konservatif. Sebaliknya pada proyektil kecepatan tinggi menghasilkan komposit yang menyebabkan kerusakan jaringan cukup besar melalui gelombang kejut dan kavitasi. Cedera ini lebih baik dinilai pada 3-4 bulan setelah cedera. Pasien dengan pemulihan minimal ataupun tanpa perbaikan sama sekali merupakan indikasi untuk terapi bedah. ${ }^{3}$

Didorong oleh hasil transfer otot gracilis untuk mengembalikan fungsi tangan di akhir tahun 90-an, Doi et al. menggambarkan pengalaman mereka dengan double FFMT yaitu menggunakan otot gracilis dan adduktor longus dalam mengembalikan fungsi fleksi siku dan tangan. Mereka mampu mengembalikan fungsi fleksi siku pada $96 \%$ pasien dan $>30^{\circ}$ dari total aktif gerakan jari dipulihkan dalam 65\% dengan double FFMT. Dodakundi et al. juga melaporkan bahwa double FFMT meningkatkan secara signifikan pemulihan fungsi pada cacat lengan, bahu serta tangan 
pada 36 pasien dengan palsi pleksus brakialis traumatis total. ${ }^{3,4}$

Sananpanich et al. mempelajari anatomi pembuluh darah gracilis dan otot adduktor longus di kadaver spesimen, dan menemukan bahwa dalam 98\% spesimen kadaver kedua otot diberi nutrisi oleh satu kesamaan pedikel vaskular. Studi-studi ini menunjukkan bahwa secara bersamaan transplantasi gracilis dan otot adduktor longus dapat dilakukan dengan sukses dengan satu anastomosis dari pedikel vaskuler proksimal. ${ }^{5}$

Penerapan terapi double FFMT ini masih sangat jarang dilakukan dan belum pernah diterapkan di Indonesia. Berdasarkan hal tersebut, keuntungan tindakan operatif ini patut diterapkan bagi pasien dengan cedera pleksus brakialis untuk mendapatkan fungsi yang lebih baik.

\section{LAPORAN KASUS}

Pasien laki laki usia 36 tahun dengan tangan dominan kanan, datang dengan keluhan utama tidak bisa menggerakkan ekstremitas atas kiri dengan riwayat mengalami kecelakaan tunggal sepeda motor 2 tahun sebelum operasi pleksus brakialis dilakukan. Pasien mengendarai sepeda motor dengan kecepatan tinggi (>100 $\mathrm{km} / \mathrm{jam}$ ). Pasien tidak dapat mengingat posisi saat jatuh karena mengalami penurunan kesadaran. Tiga jam setelah kecelakaan pasien tidak dapat merasakan dan menggerakkan ekstremitas atas kirinya. Pasien juga mengalami fraktur pada humerus kiri, antebrakhii kiri dan kruris kiri. Beberapa hari setelah kecelakaan pasien dioperasi reduksi dan fiksasi interna fraktur.

Pada pemeriksaan fisik didapatkan ekstremitas atas yang asimetris dengan atrofi otot ekstremitas atas kiri. Jaringan parut pascaoperasi fiksasi interna juga didapatkan. Defisit neurologis yang didapatkan pada pemeriksaan motorik kekuatan otot-otot ekstremitas atas kiri adalah nol (Gambar 1). Pemeriksaan sensorik menunjukkan hipoestesi pada sisi lateral lengan atas kiri, sisi dorsal dan ulnar lengan bawah kiri, serta sisi volar dan dorsal pada tangan. Tidak didapatkan tanda-tanda kelainan sindrom horner yang menunjukkan tidak adanya kelainan otonom. Secara klinis, pasien didiagnosa cedera total pleksus brakhialis kiri C5-Th1 post ganglioner.

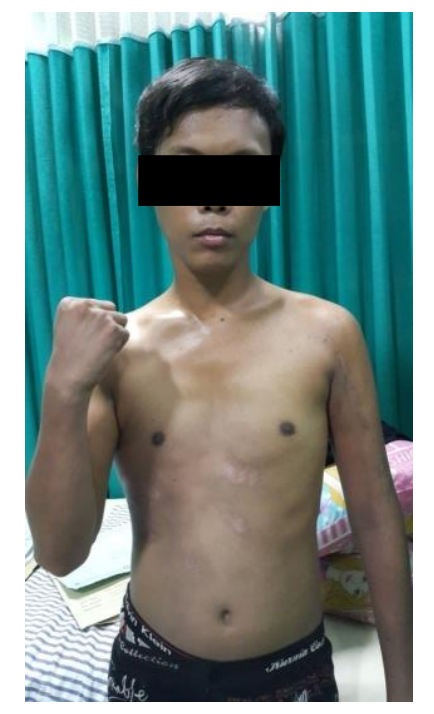

Gambar 1. Pasien tidak dapat memfleksikan siku kiri 
Pemeriksaan radiologis memperlihatkan tulang yang terpasang fiksasi interna pada humerus, antebrakhii, dan kruris kiri. Pemeriksaan EMG dan NCV menunjukkan total lesi aksonal pleksus brakialis C5-Th1 postganglioner.

Eksplorasi pleksus brakialis dilakukan pada pasien dan didapatkan ruptur total root C5-Th1. Pasien diterapi dengan transfer otot fungsional ganda (double FFMT) dengan donor otot gracilis dan otot adduktor longus sinistra (Gambar 2 dan 3). Donor vaskuler yang digunakan adalah arteri vena thorakoakromial. Donor untuk sarafnya menggunakan nervus phrenicus untuk mempersarafi otot gracilis dan nervus asesorius untuk mempersarafi otot adductor longus. Setelah vaskuler dan nervus tersambung, dilakukan tunneling tendon adduktor longus dengan origo pada prosesus korakoideus dan insersi pada bisep tendon. Otot gracilis dengan origo klavikula dan insersi dijahitkan pada tendon fleksor digitorum profundus dan fleksor policis longus.

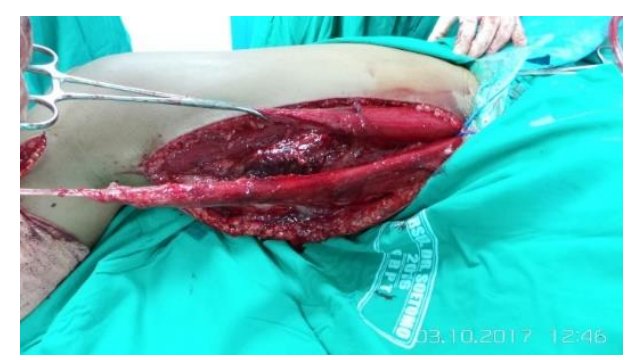

Gambar 2. Pengambilan otot gracilis dan adductor longus beserta arteri, vena, dan sarafnya

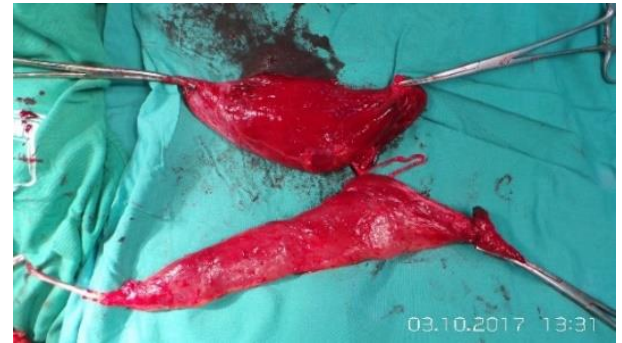

Gambar 3. Otot gracilis dan adduktor longus

Pascaoperasi, pasien diimobilisasi dengan backslab dengan posisi fleksi siku 90 derajat, supinasi lengan bawah, fleksi pergelangan tangan 30 derajat, dan fleksi metakarpopalangeal 90 derajat. Backslab dipetahankan selama 6 minggu.

Evaluasi satu tahun pasca operasi menunjukkan pasien telah mampu secara aktif melakukan gerakan fleksi dari siku dengan kekuatan skala 3 serta sedikit gerakan fleksi dari jari-jari dengan kekuatan skala 1 (Gambar 4). Pada pemeriksaan EMG-NCV setahun pasca operasi, didapatkan reinnervasi otot gracilis dan otot adduktor longus.

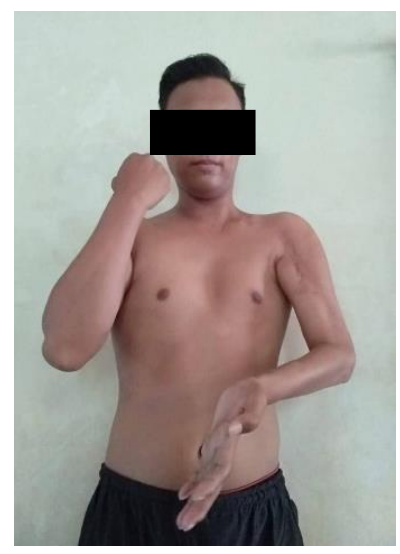

Gambar 4. Evaluasi satu tahun pasca operasi, pasien dapat melakukan gerakan fleksi dari siku dengan kekuatan skala 3 serta fleksi dari jari-jari dengan kekuatan skala 1 


\section{DISKUSI}

Cedera pleksus brakialis dapat menjadi kasus cedera yang parah dimana perbaikan fungsi jarang dapat dilakukan. ${ }^{6,7}$ Tatalaksana cedera pleksus brakialis ditentukan berdasarkan waktu pemberian terapi, segera, awal, atau terlambat. FFMT merupakan salah satu pilihan terapi pada cedera lesi brachialis. ${ }^{8,9}$ Terlihat pada riwayat perjalanan penyakit pasien bahwa cedera sudah terjadi sekitar 2 tahun yang lalu, seperti berdasarkan Yousif et al, pada kasus cedera pleksus brachialis yang terlambat, atau dengan avulsi total, transplantasi tendon atau otot secara lokal atau bebas biasanya lebih direkomendasikan. ${ }^{10}$

FFMT satu otot biasanya hanya untuk memfungsikan satu gerakan yaitu fleksi siku. Pada kasus ini, pasien diterapi dengan transfer otot fungsional ganda (double FFMT) dengan donor otot gracilis dan otot adduktor longus sinistra. Pada pilihan terapi ini diharapkan pasien tidak hanya dapat memfungsikan gerakan fleksi siku, tetapi juga dapat menggerakkan fleksi jari-jari. Otot grasilis sudah sering digunakkan sebagai FFMT karena terdiri dari jaringan seperti tendon Panjang, sistem pembuluh darah yang mencukupi, dan bentuk anatomi yang konsisten, serta lokasi pembuluh yang mensuplai nutrisi pada persyarafan di bagian pangkal. ${ }^{5,9}$ Chung et al melaporkan pasien yang menderita kontraktur ischemia Volkmann yang diterapi dengan transplantasi grasilis dan otot adduktor longus, dengan anastomoses arteri nutrisi yang terdapat pada kedua otot, untuk mengembalikan fungsi ekstensi dan fleksi jari. $^{5}$

Pada kasus cedera pleksus brakialis, mengembalikan fungsi siku adalah prioritas utama dari operasi rekonstruktif. ${ }^{11-13}$ Tindakan ini membuat ekstremitas atas dapat melakukan fungsi nya yakni gerakan tangan ke mulut untuk makan. ${ }^{14}$ Double FFMT membutuhkan waktu pengerjaan yang lebih lama dan membutuhkan donor arteri dan saraf yang ganda pula. Evaluasi satu tahun pascaoperasi menunjukkan pasien telah mampu secara aktif tidak hanya melakukan gerakan fleksi dari siku, seperti FFMT pada umumnya, tetapi juga dapat melakukan gerakan fleksi dari jari-jari. Pada pemeriksaan EMG-NCV setahun pascaoperasi, didapatkan reinnervasi otot gracilis dan otot adduktor longus. Diharapkan dengan rehabilitasi lebih lanjut dapat menambah kekuatan dari gerakan.

\section{KESIMPULAN DAN SARAN}

Tindakan double FFMT atau transfer otot fungsional ganda yang dilakukan pada cedera total pleksus brakialis C5-Th1 Post ganglioner memberikan hasil yang efektif 
untuk mencapai gerakan fungsional siku dan tangan sekaligus.

\section{REFERENSI}

1. Venkatramani H, Centre GM, Sabapathy R, Centre GM. Functioning Free Gracilis Muscle Transfer for Restoration of Elbow Flexion in Functioning Free Gracilis Muscle Transfer for Restoration of Elbow Flexion in Adult Brachial Plexus Palsy - The Ganga Hospital Approach. 2017.

2. Estrella EP, Montales TD. Functioning free muscle transfer for the restoration of elbow flexion in brachial plexus injury patients. Injury. 2016;47(11):2525-2533.

3. Maurya S, Bhandari P. Recent advances in the management of brachial plexus injuries. Indian $J$ Plast Surg. 2014;47(2):191.

4. Tu Y. Brachial plexus injury-from doubleto triple FFMT. BMC Proc. 2015;9(3 Supplement):9-10.

5. Kaizawa Y, Kakinoki R, Ohta S, Noguchi T, Matsuda S. Free functional muscle transplantation of an anomalous femoral adductor with a very large muscle belly: A case report. J Brachial Plex Peripher Nerve Inj. 2013;8(1):1.

6. Chuang DC-C. Microsurgical Reconstruction in Brachial Plexus Injury and Facial Paralysis. Transl Res Biomed. 2016;5:1-11.

7. Shen YD, Zheng MX, Hua XY, Qiu $\mathrm{YQ}, \mathrm{Hu} \mathrm{KJ}, \mathrm{Xu}$ WD. Brachialis muscle transfer for reconstructing digital flexion after brachial plexus injury or forearm injury. J Hand Surg Eur Vol. 2018;43(3):259-268.

8. Sakellariou VI, Badilas NK, Stavropoulos NA, et al. Treatment Options for Brachial Plexus Injuries. ISRN Orthop. 2014;2014:1-10.

9. Maldonado AA, Kircher MF, Spinner RJ, Bishop AT, Shin AY. Free Functioning Gracilis Muscle Transfer With and Without Simultaneous
Intercostal Nerve Transfer to Musculocutaneous Nerve for Restoration of Elbow Flexion After Traumatic Adult Brachial Pan-Plexus Injury. $J$ Hand Surg Am. 2017;42(4):293.e1-293.e7.

10. Yousif NJ, Matloub HS, Kolachalam R, Grunert BK, Sanger JR. The transverse gracilis musculocutaneous flap. Ann Plast Surg. 1992;29(6):482-490.

11. Terzis JK, Kostopoulos VK. Free Muscle Transfer in Posttraumatic Plexopathies Part II: The Elbow. Hand. 2009;5(2):160-170.

12. Nicoson MC, Franco MJ, Tung TH. Donor nerve sources in free functional gracilis muscle transfer for elbow flexion in adult brachial plexus injury. Microsurgery. 2017;37(5):377-382.

13. Sechachalam S, O'Byrne A, Macquillan A. Free Functional Muscle Transfer Tendon Insertion Secondary Advancement Procedure to Improve Elbow Flexion. Tech Hand Up Extrem Surg. 2017;21(1):8-12.

14. Hoang D, Chen VW, Seruya M. Recovery of Elbow Flexion after Nerve Reconstruction versus Free Functional Muscle Transfer for Late, Traumatic Brachial Plexus Palsy. Plast Reconstr Surg. 2018;141(4):949-959. 